\title{
EL AGUA DEL ALTIPLANO Y SU PAPEL EN LAS CONVERSACIONES CHILENO-BOLIVIANAS DE 1950*
}

\author{
THE FRESH WATER OF THE ANDEAN HIGHLANDS AND ITS ROLE \\ IN THE 1950 CHILEAN-BOLIVIAN CONVERSATIONS
}

\author{
Karen Isabel Manzano Iturra ${ }^{* *}$ y Diego Ignacio Jiménez Cabrera***
}

\begin{abstract}
En el Gobierno de Gabriel González Videla, el desarrollo industrial fue una meta clave dentro de la política económica de sustitución de importaciones. Para ello, se buscó formular e implementar un megaproyecto en el Norte Grande utilizando los planos del ingeniero Luis Lagarrigue (1922), quien propuso que se usaran las aguas del lago Titicaca para canalizarlas hacia Chile. Esto dio paso a las conversaciones de 1950, dentro de las cuales Bolivia nuevamente buscaba una salida al mar y Chile ofrecía posibilidades de solución, tales como un corredor a cambio de las aguas del Titicaca. Así, estudiamos aquel problema de investigación a través de la teoría de la geopolítica del agua por medio de una metodología cualitativa (fuentes primarias, secundarias y terciarias), especialmente para comprender el potencial de desarrollo de la rivalidad por los recursos entre Chile, Bolivia y Perú.
\end{abstract}

Palabras claves: Geopolítica del agua, conversaciones de 1950, política exterior, Bolivia, Chile.

In the government of Gabriel Gonzalez Videla, the industrial development was a central economic policy objective at import-substitution industrialization strategy. Thus, the Chilean government sought to make a megaproject at the Norte Grande by the blueprints of the engineer Luis Lagarrigue (1922), in which he proposed to utilise Titicaca Lake fresh water reserves by its channelling towards Chile. That episode gave way to the 1950 Chilean-Bolivian Talks whereby Bolivia searched for an access to the sea. Simultaneously, Chile bestowed a corridor in exchange for Titicaca fresh waters. Then, we study this research problem through the theory of geopolitics of water by a qualitative methodology (primary, secondary, and tertiary sources), especially to comprehend the development potential of the rivalry over resources among Chile, Bolivia, and Peru.

Key words: Water geopolitics, talks of 1950, foreign policy, Bolivia, Chile.

Cuando se analizan los temas del agua en cualquier parte del mundo, se debe destacar su importancia como recurso vital en la vida humana y en el desarrollo de la civilización. Así como en algunos lugares llueve todo el año y es fácil satisfacer las necesidades de la población, en otros las bajas precipitaciones generan déficits hídricos. Esto, sumado a las rivalidades entre países vecinos que se enfrentan para obtener su riqueza, hace más complejos los conflictos. Lo último se da en el desierto de Atacama y el altiplano, en los cuales las bajas precipitaciones incrementan las tensiones de las disputas entre los estados vecinos ante la mayor escasez de agua dulce. Para Franz Tamayo, intelectual boliviano del siglo XX, la relevancia del agua se resume en que "la riqueza hidrográfica de un país hace parte consubstancial de la riqueza territorial, igual que la sangre en relación al cuerpo. Tomar las aguas y pretender que no se toca el territorio; sacar la sangre y pretender que no se toca al cuerpo, es querer cubrir un crimen con una estupidez - Tamayo" (Baptista 1978:179) $)^{1}$.

En la relación chileno-boliviana han ocurrido varios incidentes en los que muchos creyeron que se podía alcanzar una solución razonable para las partes, aunque acababan por variados motivos, especialmente el poco entendimiento y el término de las relaciones diplomáticas. Empero, en este trabajo se revisarán las conversaciones de 1950, episodio en el cual el papel del agua en el altiplano alcanzó gran notoriedad ante otros aspectos y que contribuyó, tanto a la creación de la propuesta de arreglo como a su rechazo posterior. Para ello, esta investigación cualitativa se basa en el análisis histórico-geopolítico para estudiar una dimensión

\footnotetext{
* Resultado del proyecto VRID 215064041-1.0 "Relación chileno-boliviana, entre soluciones y desencuentros 1950-2013". Universidad de Concepción.

** Universidad de Santiago de Chile. Instituto de Estudios Avanzados. Santiago, Chile. Correo electrónico: karen.manzano@usach.cl

*** Universidad de Santiago de Chile. Instituto de Estudios Avanzados. Santiago, Chile. Correo electrónico: diego.jimenez@usach.cl
} 
temporal de los hechos entre 1943 y 1951 a través de tres tipos de fuentes: primarias (Archivo Ministerio de Relaciones Exteriores de Chile, Memorias de Gabriel González Videla, Memorias de Alberto Ostria Gutiérrez, y los archivos de la Corte Internacional de Justicia [CIJ]), secundarias (textos de otros autores) y terciarias (prensa de la época). Estas fuentes nos entregan el contexto de dichas conversaciones. En algunos casos, los archivos de prensa y la correspondencia personal de los autores fueron compilados por terceros (v.gr., Franz Tamayo). En otros, formularon memorias diplomáticas cuyas copias llegaron a bibliotecas chilenas (ej., Alberto Ostria) ${ }^{2}$. Luego, en el caso de la CIJ, se encuentra la correspondencia diplomática como anexos a los textos presentados por las partes en el litigio sostenido ante aquella Corte $^{3}$.

El artículo se organiza en las siguientes fases. En la primera, se describen los pasos iniciales desde los cuales el acceso a agua dulce se posiciona como parte de las conversaciones boliviano-chilenas. Luego, se definen las fases históricas en las cuales se posicionaron los proyectos de acceso al agua del lago Titicaca de Bolivia y Chile. Posteriormente, se analiza el cómo esta necesidad se canaliza a través de la vía diplomática sin éxito. Después, se revisa cómo se comunicó a la opinión pública el rechazo a las conversaciones y, finalmente, se presentan las conclusiones de este estudio.

\section{Los primeros pasos del proceso}

Durante el año 1946 el embajador de Bolivia en Santiago, Alberto Ostria Gutiérrez, comenzó a desarrollar una intensa agenda para iniciar conversaciones con el Gobierno chileno, y así obtener una solución al problema marítimo de su país. Estas gestiones se trabajaron con el gobierno de Gabriel González Videla, quien estaba muy enfocado en el ámbito internacional. Temas tales como la creación de las 200 millas de zona económica exclusiva $[Z E E]$ y el dominio antártico por medio de la instalación de bases que le permitiesen una presencia efectiva en dicha región, cobraron mucha relevancia en su agenda de Gobierno. Empero, se requiere una somera exposición acerca de la evolución del sistema internacional de la época para comprender el desarrollo de las gestiones ya referidas entre Bolivia y Chile ${ }^{4}$.
Las nuevas transformaciones generadas en el seno del sistema internacional post II Guerra Mundial exigieron el desenvolvimiento de los países latinoamericanos en un sistema de alianzas que estaba en gestación. Uno de los componentes vitales del comportamiento de política exterior de Chile y de Bolivia estuvo fuertemente condicionado por las ideas, las ideologías y las concepciones americanistas de los estados latinoamericanos, precepto relevante en el papel de la defensa de la democracia ante el comunismo, tanto desde la política nacional como internacional de Gabriel González Videla (Garay y Soto 2013:79-112). Esto último también se desarrolló en Bolivia, país que enfrentó severas convulsiones políticas durante las décadas de 1940 y 1950, las que contribuyeron a frustrar el desarrollo de la agenda de las conversaciones boliviano-chilenas de 1950 (Cortés 2015).

Otro actor relevante en aquellas conversaciones fue Estados Unidos [EE.UU] como pivote de la estrategia de seguridad hemisférica de las décadas de 1940 y 1950, centrada en el combate al totalitarismo y las ideologías subversivas en América Latina (Ortiz Sarkis, en Soto y Garay 2018:25-57), considerada por los gobernantes estadounidenses como una zona de influencia relevante para sus intereses. Aunque en la Guerra Fría existió cierta autonomía de los países sudamericanos para desarrollar sus propias agendas en política exterior, especialmente en el caso chileno (Garay y Soto 2013), la capacidad de EE.UU de "mover el péndulo" de las relaciones vecinales sudamericanas sí fue reconocida, tanto por Chile como por Bolivia, para obtener el beneplácito del Perú en las conversaciones entre los dos primeros países, y así conseguir la implementación de un corredor para Bolivia de cinco $\mathrm{km}$ al norte de Arica. Estas últimas se debilitaron aceleradamente después de un comentario emitido a la prensa estadounidense por Harry S. Truman filtrando dichas conversaciones (Soto, en Soto y Garay 2018:128-130).

Por otra parte, cabe señalar que las reuniones entre los mandatarios de Bolivia y Chile se desarrollaron con fuerza entre 1946 y 1950 de manera confidencial, para asegurar que la opinión pública no interviniese hasta que se concretaran avances significativos en la materia. Empero, en ese mismo periodo se realizaron comentarios de otros mandatarios de la región, como el general Juan Domingo Perón (Argentina) que manifestó su 
interés por conceder un puerto franco en Rosario a Bolivia. Sus declaraciones fueron analizadas por la cancillería chilena. Esto despertó el interés de la prensa boliviana por el tema "respondiendo al inquebrantable anhelo nacional" (Vidaurre 1950:178), recabando información con expertos en el tema. Una de las primeras gestiones fue realizada por el Gobierno boliviano que postuló, bajo la presidencia Hertzog, un documento que se envió a Chile. Dentro de los que puntos que se buscaba conseguir están los siguientes:

1. Obtener la inmediata cesión de los actuales almacenes donde se guardan las mercaderías en tránsito de Bolivia, en el puerto de Arica

2. Gestionar la cesión de una sección del muelle de Arica a fin de que puedan descargar las mercaderías en tránsito para Bolivia.

3. Arriendo de la sección chilena del ferrocarril Arica-La Paz para unificar la administración y gastos de explotación de esta vía.

4. Venta de la sección chilena del ferrocarril Arica-La Paz unificada y a toda la ferrovía bajo el sistema de administración boliviana (Vidaurre 1950:178).

Estos puntos demuestran que las reales intenciones del Gobierno boliviano para lograr una salida al Pacífico se situaban en el puerto de Arica, accediendo tanto a las instalaciones portuarias como del ferrocarril Arica-La Paz, es decir, del transporte de mercaderías desde y hacia el altiplano. Pero dicha situación no era aceptada por Chile, donde según el embajador Ostria Gutiérrez se inclinaría por la idea de definir un corredor. Así, se requirió establecer una serie de puntos para acercar a las partes y conseguir un consenso de hecho sobre el particular. Este proceso, definido en variadas conversaciones, terminó por fomentar la idea un corredor entre Arica y la frontera chileno-peruana. Aunque no existirían compensaciones territoriales se estableció que había interés por parte de Chile en el aprovechamiento de las aguas del lago Titicaca, aunque sin firmar documentos que crearan obligaciones formales en dichas instancias (International Court of Justice [ICJ] 2018:36-39). Luego, se suscribieron dos notas:

Como resultado de una primera etapa de la gestión, el Ministro de Relaciones
Exteriores de Chile, Horacio Walker Larraín, y el embajador Alberto Ostria Gutiérrez, suscribieron las notas del $1^{\circ} \mathrm{y}$ 20 de Junio que significaban un compromiso de ambos países para solucionar el problema de mediterraneidad boliviana (Sanabria 1988:106) ${ }^{5}$.

Las notas referidas (junio de 1950) iniciaron las conversaciones, aunque ya existían varios documentos previos a ese periodo. A juicio del canciller Horacio Walker Larraín (Canciller de Chile entre el 27 de febrero de 1950 y el 19 de junio de 1951), Chile debía "obtener las compensaciones que no tengan carácter territorial y que consulten efectivamente sus intereses" (Guachalla 1976:35), pues en las últimas reuniones el agua que se obtenía desde el lago Titicaca era una buena opción para el desarrollo industrial del país. Asimismo, este recurso permitiría la creación de hidroeléctricas que llevaran el agua desde Bolivia al norte de Chile, tanto para el aprovechamiento agrícola como de la gran minería. Por lo que, ante el llamado boliviano a negociación, el Gobierno chileno estimaba que:

Chile respondió afirmativamente e insistió en la solución de un corredor de diez kilómetros de ancho que pasará por el norte de Arica y que conectase con el altiplano. A cambio no se pidió compensación territorial, sino que el uso de las aguas del lago Titicaca (Academia de Historia Militar 2014:43).

Es aquí donde comienza a emerger el lago Titicaca dentro de la conversación, aunque dejando en claro que -en sus cartas- Luis Fernando Guachalla ya esbozaba en 1945 la posibilidad de llegar a un entendimiento por el traspaso de aguas de caudales bolivianos al sector norte chileno:

El proyecto de aprovechamiento de las aguas o rebalses del Titicaca, para proveer -bajo administración netamente boliviana- de energía eléctrica al norte de Chile, en gran escala y barata. Un proyecto de tal magnitud excluiría toda otra clase de compensación y aun el valor del ferrocarril e instalaciones ariqueñas. En realidad, entre Bolivia y el Perú deberían 
financiar la gran obra si técnicamente fuera viable, y Bolivia de lo que tocase se entendería con Chile (Guachalla 1976:9).

Por ello, se comprende que la idea de las aguas del Titicaca era anterior a las conversaciones de ese periodo. No obstante, Bolivia le ofrecía a Chile esta posibilidad, aunque un proyecto de esta envergadura debía conseguir un alto financiamiento, siendo EE.UU el más proclive para lograr tal objetivo. En efecto, la visita de González Videla a Truman en Washington fue clave en el proceso, ya que el primero logró entusiasmar con esta iniciativa al mandatario estadounidense. Empero, un punto interesante a analizar son las condiciones en las que se encontraba el lago, es decir, a quién pertenece, su ubicación y cuáles eran los reales alcances de su explotación eléctrica en aquella época.

\section{Lago Titicaca ¿desde el altiplano al Pacífico?}

El lago Titicaca es un cuerpo de agua fundamental para el altiplano, ya que se encuentra en medio de un clima agreste en el cual sus reservas han sido escasas por largos periodos de tiempo. Históricamente, su uso se remontaba al periodo precolombino, siendo pilar esencial en la cosmovisiones Tiahuanaco e Inca. Estos últimos atribuían a aquel lugar ser el punto exacto de la creación del mundo. En efecto, su situación generó intereses para los pueblos e imperios que fuesen dueños de sus aguas, aunque durante la Colonia se mantiene dentro de la unidad administrativa del Virreinato del Perú. Dicho lago se disgregó tras la independencia en dos países (Bolivia y Perú), quienes se transformaron en los competidores por dicho territorio. Dentro de su texto "El lago Titicaca, el más alto y navegable del mundo", Washington Cano explica que:

El Lago Titicaca, el más alto y navegable del mundo, se encuentra en el Altiplano del Collao, en el Sud-este del Perú, en el Departamento de Puno y Nor-este de la República de Bolivia, entre las cordilleras Occidental de Los Andes que viene de Chile y la Oriental de Bolivia, las que se unen al Norte formando el Nudo de Vilcanota en el Departamento del Cuzco. Este Lago milenario suspendido entre
Los Andes, está a 3,919 metros sobre el nivel del mar (Cano 1952:11).

Si bien se encontraba lejos de la frontera, Chile tenía intereses en el lago desde hacía décadas; en 1922 el ingeniero Luis Lagarrigue -uno de los principales promotores de obras tales como la canalización del río Maipo- había creado un plan de aprovechamiento de las aguas del Titicaca mediante una canalización desde el altiplano al Norte Grande. Estas incluían obras de regadío, hidroeléctricas y otras que requerían millones de dólares para su construcción, pero que permitían su uso en agricultura, minería e industria y con ello, el riego de numerosas hectáreas en la Pampa del Tamarugal. Un proyecto similar no se había desarrollado hasta entonces. Esta propuesta solo es comparable en la actualidad con trabajos de acueductos realizados en Paraguay o Argentina, los cuales están trasladando agua desde cientos de kilómetros para su aprovechamiento en el siglo XXI. Aunque la idea quedó en el olvido por sus pocas posibilidades de realización en esa época, treinta años después se reconsideró esta solución. En las Memorias de González Videla se explica que el:

[...] estudio efectuado por el afamado ingeniero Luis Lagarrigue, en el año 1922, que contemplaba la captación de las aguas del lago Titicaca por medio del río Desaguadero, para luego ser llevadas a través de la construcción de un canal navegable hasta cerca de la frontera chilena, y, después, por medio de un túnel de doce kilómetros de extensión, atravesaría la cordillera de los Andes para caer en la hoya hidrográfica del río Loa. Esta caída, calculada en dos mil metros, sería productora de gran cantidad de energía eléctrica, que se aprovecharía en los centros mineros e industriales y en las ciudades de Tarapacá y Antofagasta. Además, esta energía se utilizaría con fines de regadío en la Pampa del Tamarugal (González Videla 1975:895).

La posibilidad de traslado de aguas del Titicaca, aprovechando las conexiones de este lago con el Poopó y los ríos del altiplano poseía antecedentes geológicos. Es más, según Cano, el ingeniero Melo 
explicaba en su teoría terrestre de formación del lago que, en periodos geológicos anteriores, existía un gran río que corría por el altiplano conectando los ríos y lagos de la región hasta llegar al río Loa "desaguando en el Pacífico, después de haber hecho un recorrido de más de 1.350 kilómetros de extensión" (Cano 1952:21). El problema se desarrolló al generarse continuos levantamientos producto de la orogénesis de América, los que impidieron el paso de las aguas y estancándolas en una serie de lagos y lagunas que constituyen el rastro visible de este gran río. Así, mientras se desarrollaba y desechaba el proyecto Lagarrigue, Perú y Bolivia definían su frontera y el dominio de ese sector con respecto al Titicaca. En 1925, se establece el primer tratado de límites en ese sector del altiplano en los siguientes términos:

Convienen las Altas Partes Contratantes en proceder de inmediato a la demarcación de la frontera, desde donde fue iniciada por la anterior Comisión Mixta Demarcadora, o sea desde el punto en que el arroyo Pachasili confluye con el Río Suches, punto situado aproximadamente a los $69^{\circ} 8$ de Longitud Oeste del Meridiano de Greenwich y $15^{\circ} 15^{\prime} 32^{\prime \prime}$ de Longitud Sur, sirviendo ese mismo arroyo de límite entre las fincas de Tarucani y Huarachani, peruana la primera y boliviana la segunda; del referido punto se continuará la demarcación a través del territorio y del Lago Titicaca, detallándose con precisión la posición geográfica de los pueblos, islas y puertos pertenecientes a ambos países, hasta llegar al límite de los territorios ocupados por Chile conforme a la cláusula tercera del Tratado de Paz del 1883 (Ministerio de Relaciones Exteriores de Bolivia, 1925).

A partir de entonces, el desarrollo de la región se orientó a la definición de los límites exactos, siendo el protocolo de 1932 el que terminó con este problema ya que estableció, punto a punto los lugares de demarcación. Desde entonces, cualquier negociación sobre sus aguas debía desarrollarse en consulta previa con el otro Estado tras la formalización de una agenda consensuada, a fin de asegurar la propiedad del punto geopolítico más relevante de la región.

\section{La voluntad de alcanzar una solución desde las conversaciones}

Aunque las conversaciones por las aguas del lago Titicaca a cambio de una salida al mar para Bolivia tuvieron algunos puntos de discusión a inicios de los años 1940, estas últimas se mostraron con un avance más bien discontinuo antes de 1948. Es en el contexto de las conversaciones entre Gabriel González Videla y Harry S. Truman, en el cual el potencial intercambio de agua dulce por mar fue conversado regularmente. Empero, el Gobierno boliviano alegó desconocimiento de aquellas, tanto del proyecto como de su inversionista en la demanda que décadas más tarde se hizo contra Chile ante la CIJ (ICJ 2014a; I: 54) ${ }^{6}$. Sin embargo, las pruebas presentadas por Bolivia en el diferendo ya señalado indican que las gestiones de González Videla sí se le comunicaron al embajador boliviano en varias oportunidades (ICJ 2014a; II: 253-287). Es más, el presidente chileno le señaló al embajador Ostria que la cesión era más viable por un corredor al norte de Arica que por la ciudad misma, aduciendo motivos históricos y patrióticos, lo cual fue informado por el embajador Ostria al Gobierno boliviano mediante un cable (ICJ 2016:2:505-513). Esto último se señaló en el contexto de conversaciones previas, lo que se ha indicado ha sido una expresión política de voluntad de parte de Chile en el sentido de estar abiertos a una eventual negociación con Bolivia, así como escuchar y poner atención a su pretensión por un acceso soberano al mar. Empero, esta voluntad de recibir propuestas de Bolivia no generó derechos para este último sobre la zona (ICJ 2016:1:101-120).

Aunque se indica que el acceso de los lagos Titicaca y Poopó no eran materias de discusión, lo señalado por el embajador boliviano enuncia los comentarios acerca del peligro en que se encuentran las aguas del primero ante el avance de las conversaciones con Chile. Luego, dicho embajador también mencionó, en la nota confidencial 737/472 del 3 de agosto de 1950 enviada al Canciller boliviano que, al ser discutido el intercambio de acceso al mar por agua de los lagos ya referidos no eran sino una hipótesis sobre el cual no se habían hecho comentarios oficiales (ICJ 2016:2:565-573). Luego, en la nota 668/444 del 19 de julio de 1950 ya se había informado al Gobierno antes señalado de la existencia del 
proyecto Lagarrigue a través de las declaraciones vertidas por el Canciller chileno Horacio Walker Larraín a la revista Vea, publicada ese mismo día (ICJ 2016:2:551-563).

Empero, las negociaciones no mostraron mayores avances desde 1951, año en el cual se dan las mayores controversias por el acuerdo en ambos países, factor en el cual las interpretaciones de ambos países concuerdan (ICJ 2017b;I:89-102), con la salvedad de que el Gobierno chileno, conforme a Bolivia (ICJ 2017b;I:94-102), proponía su interés en una compensación económica y de recursos antes que territorial. La tesis de la compensación económica y territorial, de acuerdo a los planteamientos bolivianos, comenzó a cobrar fuerza desde el envío de la nota confidencial 455/325 del 2 de junio de 1948. Esta última, emitida por Ostria Gutiérrez (embajador de Bolivia en Chile) y dirigida a Adolfo Costa du Rels (Canciller de Bolivia entre el $1^{\circ}$ de marzo y el 9 de agosto de 1948), comenta el avance de las conversaciones con Gabriel González Videla y Germán Vergara Donoso (Canciller de Chile entre el 2 de agosto de 1947 y el 7 de julio de 1948, y del 7 al 27 de febrero de 1950), señalando el embajador boliviano que la compensación que está dispuesta a ofrecer Bolivia ante la posible salida al mar mediante un corredor a cinco $\mathrm{km}$ al norte de Arica no será territorial, sino económica o comercial (ICJ 2017b;II:167-177). Esta idea se reforzó mediante la nota estrictamente confidencial 515/375 del 28 de junio de 1948, emitida por el embajador Ostria a Pedro Zilveti Arce (Canciller de Bolivia entre el 28 de enero de 1950 al 16 de mayo de 1951), salvo la incorporación de la posibilidad de compensar financieramente a Chile por dicho acceso (ICJ 2017b; II: 179-197). No obstante, sobre estas compensaciones, Ostria Gutiérrez informó al ministro Zilveti en la nota reservada 470/322 del 27 de mayo de 1950 -que transcribe la conversación entre González Videla y Zilveti en Washington- en la cual el primero señaló que Chile no pedirá compensaciones territoriales ni económicas a Bolivia (ICJ 2017b;II:227-231).

Empero, aquella idea se deshecha al indicar Ostria en la nota reservada 510/349 del 10 de junio de 1950 que este último solicita autorización a Zilveti para incorporar en un acápite de un borrador de acuerdo que Chile podría obtener las compensaciones que no tienen carácter territorial, y que consulten efectivamente sus intereses (ICJ 2017a:2:233-239). Esto último se reafirma en la nota reservada 544/371 del 17 de junio de ese mismo año, emitida por Ostria a Zilveti, junto con la orden al embajador de Bolivia en Washington de no informar de las gestiones a Harry S. Truman (ICJ 2017b;II:251-261), dado que Chile apuntaba a hacer avances con este último presidente junto a Bolivia para lograr la aquiescencia del Perú, según lo señalado en la nota reservada 550/374 del 20 de junio emitida por Arce a Zilveti (International Court of Justice, 2017b;II:263-267). Aunque el intercambio de notas para entrar en una negociación entre Bolivia y Chile en cuanto a acceso soberano a cambio de compensación no territorial continuó copando la agenda de ambos países hasta septiembre de 1950, cuando comienza el cuestionamiento público de las conversaciones conducentes a producir una negociación formal sobre el particular (ICJ 2017b; II: 268-410).

Durante 1951, sin embargo, González Videla señala, a partir de las declaraciones del presidente Truman, que el intercambio de acceso al mar a cambio de agua dulce, especialmente de los lagos Titicaca, Coyapasa y Poopó, junto con el río Desaguadero, responde al espíritu americanista así como de la limpieza de la conducta internacional de Chile (ICJ 2017b; III: 411-425). Al respecto, el Canciller de Bolivia señaló que esta propuesta del uso de agua dulce boliviana para los propósitos ya enunciados nunca fue propuesto formalmente por el Gobierno chileno (ICJ 2017b; III: 427431). La propuesta chilena del inicio formal de conversaciones para alcanzar una negociación apuntó a acceder a las aguas del Titicaca así como de otros lagos altiplánicos, tanto por necesidades vinculadas al riego como a la hidroelectricidad (ICJ 2017a:1:73-81). Aunque la propuesta chilena fue de una connotación política, el Gobierno boliviano asumió la idea, conforme a la posición de Chile, de que aquella había generado antecedentes conducentes a un compromiso jurídico. En efecto, las propuestas difirieron tanto que la idea chilena fue rechazada, justamente, porque se planteó como compensación por un acceso soberano al mar para Bolivia las aguas del río Lauca y del lago Titicaca (ICJ 2017a:1:90-97). Mientras el caso del Titicaca fue rechazado por tener el carácter de aguas internacionales, dado que se comparten con Perú, el acceso del Lauca también fue rechazado por Bolivia en 1976 dentro de las negociaciones de Charaña (ICJ 2017a:1:112-118), lo cual da 
cuenta de la persistencia del uso del agua dulce como un problema geopolítico en la relación boliviano-chilena.

Aunque las conversaciones acerca de la superación de la mediterraneidad boliviana se retomaron desde 1940, no se plantearía la compensación para Chile en agua dulce, sino hasta la emisión de la nota confidencial 212/151 del 14 de marzo de 1950, emitida por la embajada de Bolivia para Zilveti, dando cuenta de declaraciones de González Videla en distintas instancias de las conversaciones ya referidas (ICJ 2017a:2:221-227). Luego, esta posibilidad se enuncia para los casos del lago Titicaca y el río Desaguadero en las conversaciones dadas entre González Videla y Truman en la carta estrictamente confidencial 1189/95/7 del 7 de julio de 1950, emitida desde la embajada de Chile en Bolivia al Canciller chileno (ICJ 2017a:2:255259). Estos planes fueron divulgados por el gobierno ante el Senado chileno el 6 de septiembre de 1950 en la parte secreta de la sesión $26^{\circ}$ ordinaria (ICJ 2017a:2:271-283), así como en la Reunión de Ministros de Relaciones Exteriores de las Américas del 26 de marzo de 1951 por el presidente estadounidense (ICJ 2017a:2:285289), mientras que en el telegrama 485 del 31 de marzo de 1951, emitido por la embajada de EE.UU en el Perú al secretario de Estado de este último país, se da cuenta del problema que se genera con Perú al compartir las aguas del lago Titicaca (ICJ 2017a:2:291-292).

\section{Las conversaciones fallidas: el papel de la opinión pública}

Tras los avances de las conversaciones, donde se incluía la posibilidad del corredor a cambio del uso de las aguas del lago Titicaca, el secreto que se había mantenido cambió al divulgarse en la opinión pública los alcances de las conversaciones. Esta información se publicó como trascendido en la Revista Ercilla, la cual explicó el 11 de junio de 1950 los principales detalles en un reportaje, del cual se resumen los siguientes puntos a definir por Bolivia y Chile: “a) El destino de Arica y del F. C Arica a La Paz; b) el provenir de las azufreras de Tacora, que pertenecen a Chile; c) la realización efectiva y pronta de las obras para aprovechar el agua y su fuerza, de los lagos bolivianos" (Guachalla 1976:37).
La controversia en torno a las aguas del Titicaca se desató desde esa declaración, tanto en Chile como en Bolivia. En Chile comenzaban las críticas desde el Congreso hacia el Presidente, por no incluir al poder legislativo de una situación tan delicada que involucraba los límites y fronteras del país y en Bolivia "en el transcurso de las negociaciones, Franz Tamayo saltó iracundo en defensa del lago sagrado, afirmando que "la próxima zarpada de Chile será el Titicaca” (Sanabria 1988:108). Franz Tamayo, uno de los intelectuales más importantes de ese país, marcado por las ideas del nacionalismo y el cristianismo, además de un reconocido emblema del revisionismo, que había participado en la primera demanda boliviana contra Chile ante la Sociedad de Naciones, comenzó a realizar varias declaraciones en medios públicos para manifestar su oposición al acuerdo que estaba realizando el Gobierno de la época, en especial por que se estaba incluyendo el agua del altiplano:

La agresión de 1879, preparada durante decenios, sobre todo por lo que toca a los armamentos (sic.) marítimos solo proyectó y cumplió el despojo del jirón más rico de Bolivia entonces: el litoral salitrero. Hoy es mas grave (sic.). La zarpada se dirige al corazón mismo de Bolivia: el gran lago Colla (Baptista 1978:182).

Este gran lago "Colla" otorga al Titicaca una nueva representación, como base fundamental de la cultura boliviana que estaba en juego por las conversaciones de su Gobierno. Una de sus más recordadas intervenciones, en el diario "La Ultima Hora", consagró la visión de víctima-victimario, representados en la imagen de una pobre oveja boliviana frente al gendarme chileno que le quita el agua del Titicaca. El boliviano, además de mostrar una imagen desvalida, genera una visión de permanente victimización ante el poder de Chile, representado por medio del gendarme que saca a la oveja boliviana de las aguas sagradas, señalando finalmente que:

Ahora bien, la pregunta de la propaganda en Bolivia es falsa y especiosa. No es necesario aturdir al pueblo preguntándole si quiere puerto. Hay que decirle la verdad que con una audacia estupenda ha señalado el chileno: las compensaciones. 
Entonces, la pregunta al boliviano, real y verdadera, por salvaje que parezca, es la siguiente: ¿Estas dispuesto a entregar el lago Titicaca y otros al chileno? (Sanabria 1978:108).

La visión del lago sagrado y la posibilidad de que Chile accediese a sus aguas generó una fuerte oposición de la población, que no aceptaba que esa condición le favorecería en la obtención de una meta mayor: la posibilidad del corredor a cambio del agua dulce, desechando toda opción de acuerdo entre las partes aunque esta incluyera un puerto en el Pacífico. Para Franz Tamayo, el tema creaba un dilema claro: el puerto versus el agua ya que "El corazón del continente es Bolivia, y el corazón de Bolivia es el lago Titicaca. De esa fuente mística nació el más grande imperio sudamericano. Por alguna razón sería" (Sanabria 1988:109). El arrastre y la pluma de Tamayo generaron una imagen contraria a todo entendimiento, ya que según su propia visión, el victimario (Chile) seguía explotando a su víctima (Bolivia), lo que caló hondo en la población. En efecto, la presencia de las aguas no solo generaba opiniones contrarias sino que algunos, como Fernando Diez de Medina creían que no eran necesarias, puesto que "Bolivia debe crecer orgánicamente, hacerse fuerte y un día por gravitación el puerto vendrá hacia ella" (Eyzaguirre 1967:16), esto es, fortaleciéndose hasta que Chile se acercase a negociar las soluciones. Pero las concentraciones estudiantiles en La Paz mantenían la férrea oposición con lemas como: ¡Antofagasta o nada! ¡Si nos quitaron las aguas del mar no entregaremos las del Titicaca! ¡La reivindicación es nuestro grito! (Eyzaguirre 1967:16). Aunque para algunos el ambiente pro negociación significaba una usurpación, otros como Roberto Prudencio no lo estimaban así, incluso criticando la utilización de los recursos líricos de Tamayo, ya que no ayudan a Bolivia, pues "lamentablemente debo confesar que no he hallado más que frases líricas y no es con frases líricas como se puede resolver una cuestión de tanta monta para el país. Los problemas políticos e internacionales no pueden ser tratados en verso" (Montenegro 1987:63). Así, lo que se estaba jugando eran posibilidades tangibles que se estaban desechando por la opinión de los nacionalistas, sin considerar los beneficios que podrían tener de conseguir el puerto que anhelaban para solucionar el problema marítimo. Mientras tanto, el canciller Ostria Gutiérrez se apresuraba a decir que "nada se ha convenido de los lagos bolivianos, y por lo tanto, ni una gota de agua ha sido comprometida en arreglo alguno" (Escobar 1964:158). Empero, el tercero en las conversaciones era EE.UU, donde González Videla había realizado una visita de Estado en la cual le había anticipado los detalles del diálogo con Bolivia, en especial para obtener los fondos. De esta reunión se logró saber después que:

En la primavera de 1950, González Videla encontró eco favorable tanto del presidente Truman como del Secretario de Estado, Dean Acheson, para proporcionar los recursos financieros necesarios $\mathrm{y}$ hacer frente a los elevados gastos de un nuevo puerto al norte del puerto de Arica, obras de regadío y proyectos económicos de integración (Pinochet de la Barra 1987:70).

Cuando se difundió a la opinión pública los principales datos de las conversaciones, se emitieron nuevas declaraciones del mandatario norteamericano que siguieron complicando la tensa situación, ya que en 1951 "Harry Truman confirmó que Bolivia y Chile habían hablado de la utilización de las aguas de los altos lagos de Bolivia y Perú" (Sanabria 1988:107) para crear este "vergel" en las zonas del norte de Chile, favoreciendo las actividades agrícolas, mineras e industriales, mostrándose impresionado por las labores que se realizarían para este proyecto. Sin duda, el interés estadounidense en las conversaciones se generaba en un periodo donde obtendrían beneficios económicos de ellas, pues la producción de energía eléctrica que contemplaba en este plan otorgaría energía a las empresas mineras de la zona, especialmente en el cobre (Chuquicamata). En estas condiciones mejorarían las faenas cupríferas, generándose una inversión del Gobierno estadounidense ya que los mayores beneficiarios serían sus capitales mineros apostados en esa zona.

Las declaraciones de Truman fueron consideradas una intromisión y las conversaciones fracasaron cuando Chile comprobó que Bolivia se desdecía de sus propias acciones, declarando que jamás ofreció las aguas de los lagos del altiplano como parte de la compensación, ya que "la 
cancillería boliviana confirmó en parte la información pero, aclarando que el caso de la utilización de las aguas del lago no había sido oficialmente propuesto por el Gobierno de Chile" (Sanabria 1988:107). Así, se abrió un nuevo frente en la relación, ya que las declaraciones de los personeros bolivianos muestran que ellos ya evaluaban esta posibilidad desde 1945. Además, surgió un nuevo problema con Perú, que estaba involucrado en cualquier solución debido a que es "copropietario del Titicaca, cuyas aguas no era posible ceder sin expresa autorización suya" (Sanabria 1988:107).

El Gobierno de Odría se manifestó contrario al uso de las aguas del lago, ya que su propiedad se había regulado por los convenios bilaterales de 1925 y 1932, los cuales definieron la línea divisoria de esta hoya. Luego, las declaraciones de Conrado Ríos Gallardo en "El Diario Ilustrado" tensaron aún más las conversaciones. En ellas, el ex canciller manifestó que se ponía en juego el Tratado de 1929, al ceder el corredor en antiguos territorios peruanos. Asimismo, comenzaron a surgir rumores en Bolivia, esparcidos por aquel periódico, de que en Perú eran muy favorables a la posibilidad de entregar un puerto a Bolivia siempre que se obtuviese la cesión de Chile a Perú de Arica y, aprovechando la copropiedad de los lagos Titicaca y ríos vecinos, los cuales "podrían complementar un convenio para llevar las aguas de ese lago sobre el norte de Tacna y Arica para irrigar extensas zonas y al mismo tiempo para el establecimiento de poderosas usinas eléctricas" (Baldivia 1951:345).

En medio de esta situación, González Videla emitió una declaración formal, explicando al país los principales puntos de sus conversaciones con Bolivia. En ella, analizó los alcances de dicha negociación. Además de señalar que Chile está dispuesto a escuchar a Bolivia en el marco del respeto de los tratados internacionales válidos y vigentes, uno de los primeros puntos que se excluyó fue el del puerto de Arica. Posteriormente sobre el tema del agua señaló:

Siempre que Bolivia ha puesto en actualidad su deseo de obtener una salida al mar, se ha pensado, como es natural, en lo que este país podría ofrecernos como compensación, en el caso de que llegara a un acuerdo sobre este particular con Chile y con Perú, país este último con el cual, de conformidad con los términos del Tratado de 1929, seria preciso (sic.), en ese momento oportuno entrar en conversaciones.

[...] Para Chile el aprovechamiento de la fuerza hidroeléctrica de los Lagos del Altiplano no solo nos da la posibilidad de irrigar las áridas tierras de la esforzada zona del norte, de proporcionar energía abundante al cobre y el salitre, disminuyendo sus costos de producción, sino que es el fundamento indispensable para crear la industria química pesada, que solo espera energía a bajo costo y abundante para desarrollar el proceso técnico de transformación de los salares y subproductos del salitre (Ministerio de Relaciones Exteriores 1951:27-28).

Pero no todas las visiones desde Chile eran proclives al proyecto. Según algunas opiniones vertidas en la prensa de la época como en la Revista Ercilla, se indicaban las incapacidades técnicas de desarrollar una obra de esta envergadura. Por ejemplo, el ingeniero Alfredo Sundt, calculó que los costos eran altos, debido a la inversión en los desniveles de la zona, las dificultades técnicas en el transporte del agua (que solo podrían llegar al departamento de Arica y como electricidad a Tarapacá y Antofagasta), como también "las aguas del Poopó son salobres, y por lo tanto, menos adecuadas a otros usos" (Baldivia 1951:340) lo que generaba más complicaciones en su traslado. Fue entonces que toda conversación cayó en compás de espera, del cual no se volvió a reactivar, en especial por que la oposición de la gente, expresada en las opiniones del congreso e intelectuales de ambos Estados, favoreció que las negociaciones comenzaran a estancarse, lo que se consolidó tras las inestabilidades internas de Bolivia que provocaron la revolución de 1952, en donde se comenzó el proceso de modernización de aquel estado y de inclusión de los diferentes estamentos de la sociedad en la política del país. En efecto, "dichas negociaciones fracasaron debido a la oposición de sectores de la ciudadanía de Arica y La Paz, ante lo cual Chile aparecía en una actitud abusiva respecto de Bolivia, según expresiones del escritor boliviano Franz Tamayo" (Molina Monasterios 2014:103), prevaleciendo la visión de víctima-victimario en Bolivia. 


\section{Conclusiones}

Por medio de este artículo, que analiza los principales aspectos de las conversaciones chileno-bolivianas de 1950, podemos observar la relevancia del dominio del agua, un recurso vital y escaso en esa latitud para las agendas de ambos países involucrados. No obstante, resulta necesario comprender los alcances de esta negociación desde una perspectiva de política exterior como la geopolítica del agua, lo cual nos permite entender los alcances del dialogo entre naciones. Así:

El control del agua en América el sur, representa el control de una de las principales fuentes renovables de agua dulce del planeta, de un enorme potencial de energía hidroeléctrica, el control de uno de los sistemas ecológicos de mayor concentración de biodiversidad del mundo, a partir de la floresta amazónica, los pisos ecológicos de la región andina, los grandes lagos de la Patagonia y los lagos interandinos (Bruckmann 2012:138).

Uno de los puntos más complejos dentro de la región son los lagos interandinos a partir de los cuales se ha generado una representación en torno a las civilizaciones surgidas a su alrededor a lo largo de los siglos. Por ende, en este análisis geopolítico podemos clarificar varios elementos, tales como los actores (Chile, Perú, Bolivia, EE.UU) quienes buscan establecer su poder (político y económico) en esta área (Lago Titicaca, cuencas del altiplano). Así, podemos observar que aquí se presentan elementos de la geopolítica clásica y de la nueva, ya que se revisa un área valiosa y relevante no solo por constituir un área central sudamericana (heartland) sino que el agua se transforma en el punto vital de la sobrevivencia de los habitantes de la zona. El agua del Titicaca se convirtió en la moneda de cambio que desde Bolivia, surge como opción de negociación con Chile. Sin embargo, las conversaciones fracasaron en razón de las presiones internas, en especial cuando Bolivia colocó reparos a la utilización del lago Titicaca para la generación de energía eléctrica, debido a que la visión emotivista se impuso frente a las conversaciones, siendo Chile representado como usurpador de las aguas del lago
Colla. Esto, a juicio de Tamayo, constituye una afrenta al corazón de Bolivia. Mientras tanto, en Chile las discusiones se concentraron en la actitud del presidente González Videla con respecto al Congreso, que rechazó cualquier arreglo ante la falta de información, en especial porque la prensa obtuvo primero los pormenores de esta noticia. Luego, la revolución de 1952 terminó cerrando las conversaciones.

Así, concluimos que las conversaciones de 1950 son una muestra de la voluntad de obtener soluciones satisfactorias, cuyos inconvenientes y falta de apoyo se originaron en la propiedad del agua del altiplano, un lugar que por sus características geográficas guarda en su interior este importante recurso. Actualmente el agua es un bien cada vez más escaso, incluso en Bolivia, donde la falta de una adecuada planificación terminó en la desaparición casi completa del lago Poopó, uno de los componentes esenciales del sistema hidrológico del altiplano.

En síntesis, el conjunto de proyectos de utilización del lago Titicaca sin referencia alguna al Tratado de 1904 constituye uno de los fenómenos más llamativos de búsqueda de soluciones que hasta la actualidad, son muestra de que la geopolítica del agua y el altiplano están unidas desde un largo tiempo. Esto se ve reflejado en la obligación que adujo Bolivia en la demanda de la CIJ cuando buscó utilizar las conversaciones del 1950 como una negociación que entregó obligaciones a Chile, lo que fue desechado por los jueces, ya que se adujo el principio de buena fe en cualquier deliberación política entre estados, lo que no constituyó una obligación jurídica de Chile hacia Bolivia durante el proceso, dada la inexistencia de una agenda política bilateral legalmente suscrita por las partes.

\section{Agradecimientos}

Los autores agradecen los comentarios y observaciones de los evaluadores anónimos dispuestos por la Revista. Asimismo, los autores dan las gracias a la Agencia Nacional de Investigación y Desarrollo (ANID, ex CONICYT) por el apoyo financiero brindado por los programas de becas nacionales de doctorado de los años 2016 (Karen Manzano, COD 21161675) y 2017 (Diego Jiménez, COD 21171039). 


\section{Referencias Citadas}

Academia de Historia Militar

2014 Chile-Bolivia. Breve historia de sus controversias. Salesianos Impresores, Santiago, Chile.

Baldivia, J.

1951 La tradición portuense de Bolivia. Empresa Editora Universo. La Paz, Bolivia.

Baptista, M.

1978 Tamayo y la reivindicación marítima boliviana. Litografías e Imprentas Unidas, La Paz, Bolivia.

Bruckmann, M.

2012 "La geopolítica del agua y los desafíos de la integración sudamericana”. Comunicación y política. 30. 125-142.

Cano, W.

1952 El lago Titicaca. El más alto navegable del mundo. Edición Moreno. Buenos Aires. Argentina.

Cortés, Milton

2015 "En torno de las conversaciones de 1950. La política hacia Bolivia de Gabriel González Videla: 1946-1952". Si Somos Americanos 15.2: 149-171.

Escobar Cusicanqui, J.

1964 El derecho al mar. Juventud, La Paz.

Eyzaguirre, J.

1967 El intento de negociación chileno-boliviana de 1950 y su secuela. Editorial Jurídica de Chile, Santiago, Chile.

Garay, G. y Soto, A. 2013. Gabriel González Videla "No a los totalitarismos, ya sean rojos, pardos o amarillos...”. Centro de Estudios Bicentenario, Santiago de Chile.

González Miranda, S. y Ovando C.

2016 "Emotivistas bolivianos en la relación diplomática entre Bolivia y Chile en torno a la mediterraneidad". Estudios Internacionales: 48. 183: 39-65.

González Videla, G.

1975 Memorias. Editorial Gabriela Mistral. Santiago.

Guachalla, L.

1976 La cuestión portuaria y la negociación de 1950. Editorial Los Amigos del libro, Cochabamba, Bolivia.

International Court of Justice

2014a Obligation to negotiate access to the Pacific Ocean (Bolivia v. Chile). Memorial of the Government of the Plurinational State of Bolivia. International Court of Justice, The Hague, Netherlands. Three Volumes.

International Court of Justice

2014b Obligation to negotiate access to the Pacific Ocean (Bolivia v. Chile). Preliminary Objection of the Republic of Chile. International Court of Justice, The Hague, Netherlands. Three Volumes.

International Court of Justice

2016 Obligation to negotiate access to the Pacific Ocean (Bolivia v. Chile). Counter-Memorial of the Republic of Chile. International Court of Justice, The Hague, Netherlands. Six Volumes.
International Court of Justice

2017a Obligation to negotiate access to the Pacific Ocean (Bolivia v. Chile). Rejoinder of the Republic of Chile. International Court of Justice, The Hague, Netherlands. Three Volumes.

International Court of Justice

2017b Obligation to negotiate access to the Pacific Ocean (Bolivia v. Chile). Reply of the Government of the Plurinational State of Bolivia. International Court of Justice, The Hague, Netherlands. Five Volumes.

International Court of Justice

2018 Obligation to Negociate Access to the Pacific Ocean (Bolivia v. Chile). Judgement. International Court of Justice, The Hague, Netherlands.

Ministerio de Relaciones Exteriores

1951 Memorias. Ministerio de Relaciones Exteriores. Santiago. Chile

Ministerio de Relaciones Exteriores de Bolivia

1925 Protocolo para el estudio de demarcación de la frontera de Perú y Bolivia. La Paz. 2 de junio.

Molina Monasterios, S.

2014 Cuadrar el círculo: las propuestas de solución al conflicto entre Chile y Bolivia. LOM, Chile.

Montenegro, W. 1987. Oportunidades perdidas, Bolivia y el mar. Editorial Los Amigos del Libro, Cochabamba, Bolivia.

Ortiz Sarkis, M.

2018 "El sistema de seguridad hemisférico: Trayectoria de una subordinación". En Internacionalismo y anticomunismo en tiempos de Gabriel González Videla, editado por Cristián Garay y Ángel Soto, pp. 25-57. RIL Editores, Santiago, Chile.

Pinochet de la Barra, O.

1987 ¿Puerto para Bolivia? Centenaria negociación. Editorial Salesiana, Santiago, Chile.

Ross, C.

2016 "La política chilena hacia Bolivia, 1900-1930: la constitución de un discurso estructural". Si somos americanos. 16. 1: 181-210.

Sanabria, F.

1988 El Mar Boliviano. Proinsa. La Paz, Bolivia.

Soto, A.

2018 "Como sabíamos que venías, te hicimos un pastel. El viaje a Estados Unidos". En internacionalismo y anticomunismo en tiempos de Gabriel González Videla, editado por Cristián Garay y Ángel Soto, pp. 107-144. RIL Editores, Santiago, Chile.

Vidaurre, J.

1950 Puerto para Bolivia. Antecedentes diplomáticos. Bases de negociación. Editorial Universo. La Paz. 


\section{Notas}

1 Mariano Baptista Gumucio (1933 -) es uno de los mayores historiadores y escritores bolivianos. En el libro citado más arriba, este autor compila todas las notas de prensa del diplomático Franz Tamayo obtenidas de fuentes bolivianas no asequibles en Chile. Estas fuentes las compila sin edición, y están focalizadas a dar a conocer el pensamiento de aquel diplomático sobre diversas materias, especialmente de la relación boliviano-chilena.

2 La costumbre más común en este tipo de fuentes (memorias) es que se producen con mucha posterioridad respecto de los hechos acontecidos, o bien, se publican de forma póstuma. Empero, esto no les resta mérito científico, por cuanto se publican numerosas fuentes primarias dentro de ellos (cables, cartas, borradores de notas de prensa, entre muchos otros). Así mismo, se revelan hechos o conversaciones que no están disponibles en archivo diplomático alguno. Este es el caso de Alberto Ostria Gutiérrez, embajador de Bolivia en Chile entre 1946 y 1952.

3 Los textos oficiales que se presentan ante la Corte son los siguientes: demanda; excepciones preliminares (opcional); memoria; contramemoria; réplica; dúplica; sentencia. Entre la dúplica y la sentencia se contemplan sesiones de alegatos orales, los que se publican cuando la Corte lo estima pertinente.

4 La posición de Bolivia ante las propuestas chilenas de solución a la mediterraneidad del primero se dividen en tres enfoques: 1) practicistas, quienes adscriben a la idea de dialogar con Chile para obtener cualquier solución que implique acceso soberano al mar; 2) revindicacionistas, quienes no aceptan otra salida que no sea por Antofagasta o Mejillones, en el espíritu del antiguo departamento del Litoral, y; 3) emotivistas, quienes solo exigen un acceso soberano al mar sin condiciones y sin exigencia alguna de compensación de parte de Chile (González y Ovando, 2016; Ross, 2016).

5 Floren Sanabria es escritor y fundador de la empresa editorial Proinsa. Mediante el texto que se cita en este artículo, Sanabria se refiere a numerosas fuentes primarias que explican la extensión, alcance y fundamentos del mar boliviano desde la perspectiva de un manual educativo de uso en Bolivia.

6 La CIJ, para el litigio entre Bolivia y Chile, emplea la siguiente estructura, común a todas las fases del proceso: 1) presentación de las delegaciones; 2) expresión de la pretensión máxima de la parte autora de cada documento; 3) exposición del contexto histórico y los argumentos de derecho de las partes mediante un análisis hermenéutico de la documentación probatoria, todo lo cual se hace en inglés en tanto uno de los dos idiomas oficiales de la Corte (el otro es el francés); 4) se anexan los volúmenes de todas las pruebas diplomáticas, cartográficas u otras estimadas sustanciales por las partes en español, a las cuales se adjunta una traducción oficial de éstos al inglés validada por la Corte. Para estos efectos, se citan los documentos probatorios en español, en virtud de que es este el idioma oficial de los países en controversia, metodología aceptada por la Corte. 